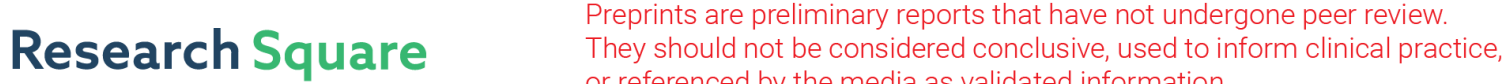 or referenced by the media as validated information. \\ Analyze the Outbreak of COVID-19 in Wuhan City Based on Large-Scale Events and Extreme Weather
}

De-ming Xie ( $\nabla$ hanzuren@zjut.edu.cn )

Zhejiang University of Technology https://orcid.org/0000-0002-2480-3452

\section{Tianyu Wang}

Zhejiang University of Technology

Hai Liu

Xinjiang Medical University

Pan Jiang

Hangzhou Municipal Real Estate Development Co., Ltd.

\section{Research Article}

Keywords: Wuhan city, large-scale mass activities, extreme climatic, seafood market, COVID-19, SARSCoV-2, mutations

Posted Date: January 10th, 2022

DOI: https://doi.org/10.21203/rs.3.rs-1201360/v1

License: (1) (1) This work is licensed under a Creative Commons Attribution 4.0 International License. Read Full License 


\section{Abstract}

This article analyzes the impact of large-scale mass activities and extreme weather on the outbreak of COVID-19 in Wuhan, confirming that the South China Seafood Market is indeed the origin of the Wuhan epidemic, and found that the probability of respiratory transmission is low in open space, while food transmission is possible. At the same time, it was found that the outbreaks of SARS in Beijing in 2003 and COVID-19 in Wuhan in 2019 were both related to extreme weather. By investigating genomics and epidemiological data, it was determined that the first COVID-19 case in Wuhan was in November, and the beginning of the epidemic was in late November. Comparing the climate of November, December and January in Wuhan from 2011 to 2020, it is found that there are a lot of extreme weather events in Wuhan from the end of 2019 to the beginning of 2020, including strong winds, heavy rains, large cooling after continuous high temperature, and continuous low temperature and rainy after large cooling, the temperature suddenly rises and then drops rapidly, the wind continues to weaken for many days and then suddenly increases, and long rainy days, etc.

\section{Introduction}

According to the WHO-China joint research report (Joint Report) [1] and the multi-center origin theory of COVID-19 [2-5], the seafood market in Wuhan is not the birthplace of the new crown epidemic. Therefore, what this article is trying to solve is not the origin of COVID-19, but the question of why Wuhan became the largest outbreak point in the early stage of the epidemic. The novel coronavirus pneumonia epidemic is affected by multiple factors such as virus subspecies, geography, climate (temperature, precipitation, wind speed, etc.), population (population composition, density and mobility), public health conditions, politics and culture. Among them, the relationship between large-scale events in Wuhan and the epidemic has not been studied in detail.

Most studies have shown that the occurrence, development, and spread of diseases, especially infectious diseases, are closely related to meteorological conditions, including human coronavirus. The reason is that meteorological factors not only directly affect the reproduction and spread of biological pathogens, but also can affect the resistance of susceptible populations [6-17]. Many articles have studied the relationship between Wuhan weather and COVID-19 [6-11]. These articles have noticed 2 points: (1) As the capital of Hubei Province and one of the largest cities in Central China, Wuhan is located in the middle of the Yangtze River Delta, which has a typical subtropical, humid, monsoon climate with cold winters. Cold and humid, dense population, and developed transportation are favorable factors for the outbreak of COVID-19 in Wuhan. (2) From July 20 to the end of November 2019, the temperature in Wuhan was higher than normal. In November 2019, Wuhan's climate changed significantly: the first ten days were dry and warm, there were one strong cold air and two cold waves in the middle and late ten days, and there was light to moderate rain in the second ten days. The temperature from December 1st to 15th was higher than that of previous years, and it was a rare warm winter without rainfall. It was rainy and rainy in January 2020. However, these articles lacking the analysis of detailed description and several key points. Generally, lower respiratory tract infections in Wuhan usually occur from December of the first year to 
April of the second year, and the incidence of lower respiratory tract infections is at most January of the second year [12]. The outbreak time of COVID-19 and previous lower respiratory diseases are not significantly different. However, COVID-19 has never been an epidemic in humans. In other words, these articles can only explain how the old epidemic spread, not how the new epidemic arose from nothing.

The spread of SARS in Mainland China has formed two export clusters centered on Beijing and Guangdong Province. Guangdong is the origin center of SARS, but there is no significant spread of radiation around it, and Beijing not only has the more serious epidemic situation, but also has significant space radiation spreading ability [18]. Wuhan is not the origin point but the second outbreak point, and a large number of extreme weather events also occurred at the beginning of the epidemic. Therefore, studying the relationship between extreme weather in Beijing and the SARS outbreak is of great help in studying the cause of the COVID-19 outbreak in Wuhan.

In response to the above problems, this article intends to study in detail the relationship between largescale events and extreme weather in Wuhan and the epidemic, which has useful implications for clarifying why COVID-19 outbreak in the world and help prevent the next outbreak of an epidemic.

The weather data comes from the weather website (https://www.tianqi.com). The data for the three days of 2012.1.15, 2020.1.6 and 2020.1.7 are missing, and the data is supplemented by the Weather Post website (http://www.tianqihoubao.com).

\section{When Did The Covid-19 Outbreak Start In Wuhan?}

Joint Report indicated that there is no unrecognized circulation of SARS-CoV-2 in Wuhan Within two months before the outbreak in December 2019 [1]. There were earlier reports suggesting the first case could be traced back to Dec. 1 in Wuhan city in the scientific literature [19] or Nov. 17 in Hubei province in the newspaper reports [20]. Lin et al. [21] estimate the number of cases that should be reported in Wuhan by 10 January 2020, as 3229, based on the confirmed cases outside Hubei province that left Wuhan by 23 January 2020. The date of first infection is estimated as 30 November 2019. Time-resolved phylogeny analyses have inferred the time of the most recent common ancestor of all sequenced SARS-CoV-2 genomes to be in November [22-26], and the earliest occurred in the first ten days [26]. Wertheim et al.

[27] analyzed the virus's genetic information and conducted epidemiological computer simulations, which put the virus's origin date at between mid-October and mid-November 2019. On December 8, 2019, a patient from the seafood market in Wuhan was admitted to the hospital for 7 days of fever, cough and dyspnea [28]. Because the median time from the first symptom to dyspnea is 5.0 days [29], this person may have onset around November 26. According to the above evidence, it can be concluded that the first case occurred in Wuhan in November, and the outbreak began in late November.

\section{Large-scale Events And The Covid-19 Outbreak}


The first four hospitals to receive COVID-19 patients were Wuhan Youfu Hospital, Wuhan Red Cross Hospital, Hubei Province Xinhua Hospital, and Wuhan Central Hospital (Houhu District) [30-32]. In late December, Wuhan Xiehe Hospital and Wuhan Tongji Hospital also received COVID-19 patients. Tongji and Xiehe are major hospitals, and patients with serious illnesses will choose these two hospitals [30]. Eventually, most patients will be referred to Wuhan Jinyintan Hospital, a specialist hospital for infectious diseases [31]. The distances from Youfu, Red Cross, Houhu, Xinhua, Xiehe, Tongji, and Jinyintan to the seafood market are $0.06 \mathrm{~km}, 1 \mathrm{~km}, 1.2 \mathrm{~km}, 1.6 \mathrm{~km}, 3.7 \mathrm{~km}$, and $4.3 \mathrm{~km}$ respectively. Hankou Railway Station is $0.6 \mathrm{~km}$ from the seafood market. Youfu is the closest to the seafood market and is also the first hospital to receive COVID-19 patients. The first hospital to report the epidemic was Xinhua. Li Wenliang, the first to disclose the epidemic, was a doctor from Wuhan Central Hospital [32].

The development trend of the Wuhan epidemic is from the periphery of the seafood market to the area along the Yangtze River. A relatively concentrated high-incidence area is formed near the Baibuting community. There is no large-scale tertiary general hospital near the Baibuting community, and the spread of the epidemic is most likely related to the public event "Banquet for ten thousand families". On January 18, 2020, the "Banquet" in Baibuting Community was held, with more than 40,000 residents participating [33]. In addition to the Banquet, the large-scale events held in Wuhan during the early stage of the epidemic included the East Lake Lantern Festival $[34,35]$ and the Hubei Spring Festival group visit theatrical performances [36]. On December 31, 2019, the 6th Lantern Festival opened, and more than 20,000 tourists were received during the opening two days [34]. On January 17, 2020, the Small New Year's Eve of the Lantern Festival was held [35]. On January 22, Wuhan City issued a notice on the suspension or cancellation of cultural tourism activities and cultural performances where people gather [38]. Therefore, the end date of the Lantern Festival is 2020.1.21. The opening day of the Lantern Festival was much earlier than the Banquet, and its duration and number of participants far exceeded the Banquet. The Lantern Festival is held in the Tingtao Scenic Area of East Lake, which belongs to the city center. During the duration of the Lantern Festival (2019.12.31-2020.1.23), there was no major cooling weather, but 16 days of rain fell. The weather on January 17 and 18 was: $7^{\circ} \mathrm{C} /-1{ }^{\circ} \mathrm{C}$, cloudy, northerly wind $1-2 ; 8{ }^{\circ} \mathrm{C} /-1{ }^{\circ} \mathrm{C}$, cloudy, northeasterly wind $1-2$. The weather on the day of the Banquet was fair, but the weather was not good for most of the duration of the lantern festival. The Lantern Festival did not promote the epidemic. On January 21, the theatrical performance of the Hubei Spring Festival group visit was held in Hongshan Auditorium. Large-scale performances with dense crowds and audiences sing along may be conducive to the spread of the virus through droplets. However, Hongshan Auditorium did not form a concentrated area of the epidemic. Baibuting, Hongshan, and Tingtao are 6.5, 11.7 and 12.2 kilometers away from the seafood market respectively. Both the Lantern Festival and theatrical performances take place in the city center. A large number of documents indicate that the COVID-19 epidemic generally occurs in the city center, while the seafood market and Baibuting are on the edge of the city, indicating that the respiratory tract transmission in the open space is less likely to spread, while food transmission is an important way of epidemic spreading.

From October 18th to 27th, 2019, the 7th World Military Games was held in Wuhan, with 9,308 soldiers from 109 countries participating [37]. Participants concentrated in the military village on the southeast 
bank of Huangjia Lake in Jiangxia District. Junyun Village is $21.8 \mathrm{~km}$ from the seafood market. The possibility of the spread of the virus by the athletes of the Military Games can be ruled out. There are two reasons: (1) It is almost impossible for the Wuhan epidemic to start in October 2019. (2) The vicinity of Huangjia Lake and the large hospitals that receive athletes, such as Jinyintan Hospital, were not the outbreak centers at the beginning of the epidemic. In summary, the seafood market is indeed the starting point of the Wuhan epidemic. Wuhan Roulian Food Co., Ltd. is an upstream enterprise in the seafood market. Although there is no report on the connection between Wuhan Roulian Food Co., Ltd. and the epidemic, its role is worth studying. Wuhan Roulian Food Co., Ltd. is 9.9 km from the seafood market.

Figure 1 shows the geographic information of the South China Seafood Market, hospital, Baibuting, etc. related to the outbreak in Wuhan.

\section{Correlation Between Extreme Weather And Sars And Covid-19 Pandemic}

\subsection{SARS in Beijing in 2003}

In the spring of 2003 in Beijing, the remaining cold of the severe winter in 2002 was still there. Beijing stopped heating supply on March 15, and people felt it was cold. It was from this day or so that Beijing ushered in a SARS outbreak.

From the winter of 2002 to the spring of 2003, the climate in China was characterized by large fluctuations in temperature and severe changes on many occasions. In the main epidemic area, western South China, the temperature in spring is lower than usual, while the temperature in most parts of China is higher than usual [16]. Gao et al. [17] analyzed the humidity, rainfall, air humidity and wind speed in the winter of 2002 and the spring of 2003 (November 6, 2002 to June 5, 2003) in Beijing for a total of 201 days. The climatic characteristics of the period are summarized as follows: Compared with previous years, the average maximum temperature is lower and the average minimum temperature is higher, the temperature is generally lower, and the temperature fluctuates greatly; the rainfall and air humidity are higher, and the wind speed is lower. The obvious increase in temperature and rainfall occurred after March 6. The abnormal climate change in the Beijing area in the winter of 2002 and the spring of 2003 may be an important factor that caused the SARS epidemic in the Beijing area in 2003. Zhang Yanling et al. [13] also pointed out that the development of the SARS epidemic in Beijing is related to high temperatures, humid air, and variable weather. The average temperature in Beijing in mid-January reached $-0.1^{\circ} \mathrm{C}$, the highest since 1916 in the same period. The average temperature in February was $1.8^{\circ} \mathrm{C}$ higher than the historical average. In the spring of 2003 in Beijing, there were three cases where the temperature difference was greater than $15^{\circ} \mathrm{C}$ in a short period of time [38]. Beijing has always been dry in spring, with high humidity in spring 2003 [13]. The precipitation in the winter of 2002-2003 was 17.8 $\mathrm{mm}, 85 \%$ more than normal $(9.6 \mathrm{~mm})$. The precipitation in Beijing in March 2003 was $32.8 \mathrm{~mm}, 295.2 \%$ more than normal $(8.3 \mathrm{~mm})$. A total of 11 snowfalls or rains occurred in March. Among them, a moderately rainy weather with precipitation of up to $16.7 \mathrm{~mm}$ occurred on March 19, which is rare in the 
same period in history. The precipitation in the middle of the observatory is $31.7 \mathrm{~mm}$, which is the highest value in the same period since the observation record of precipitation in 1875. Due to the heavy rainfall, there were more foggy days in the spring of 2003. Beijing is usually windy in spring, and there are more windy days, but in the spring of 2003, the wind in Beijing was weak and there was not a single dusty weather [39].

"Frozen three feet is not a day's cold." The SARS incident in Beijing in 2003 was a qualitative change, while the quantitative change began in 2002. In 2002, the weather in Beijing set several hundred-year records, which is relatively rare in recent years [40]. Weather terms such as warm winter, rainy season, sauna, cold winter, cloudy and snowy days have become popular words in common people's lives. The autumn of 2003 in the capital was extremely short, and the winter quickly approached. The average temperature in October is the lowest since 1925 in the same period. The average temperature in late October was the coldest record for the same period since 1940. On October 27, the daily average temperature at the Observatory in the city was $2.0^{\circ} \mathrm{C}$, which was the lowest day in the same period since 1949; the lowest temperature on October 29 was minus $3.4{ }^{\circ} \mathrm{C}$, which was the second lowest temperature in late October since 1953. From December 2002 to February 2003, the winter in Beijing was severely cold. Since December 18, 2002, there have been six consecutive days of snowfall, setting the longest number of snowfall days since Beijing had a meteorological record. The snowfall in Beijing is the largest in the past 50 years. In history, there were only 4 consecutive days of snowfall in 1916 and 1968, respectively.

\subsection{COVID-19 in Wuhan from 2019 to 2020}

Most studies have found that temperature is the most significant factor affecting the COVID-19 epidemic [41-45]. In general, as the temperature increases, the survival rate of the virus will decrease [43]. Research by Riddell et al. [44] showed that low temperature is beneficial to the survival of SARS-CoV-2 virus. The South China Seafood Market, Beijing Xinfadi Wholesale Market, and Dalian Kaiyang Seafood Company's epidemic are all related to the transportation of cold chain food. The low-temperature and humid environment greatly prolongs the life cycle and spreading distance of the virus.

During SARS period, the air quality in surrounding cities such as Shenzhen, Zhuhai, Zhongshan, Foshan, and Dongguan was better than that of Guangzhou, but SARS broke out in surrounding cities [15]. In recent years, China has been vigorously focusing on environmental protection, and in fact, air quality has improved greatly. At least, the air quality in Wuhan in 2019 and 2020 is better than in previous years, so it will not be a special factor.

The consensuses obtained from the analysis of synoptic and climatic features during SARS spreading in China 17 years ago are as follows: The average temperature of winter in 2002 is higher than in former years. There is a remarkable temperature-dropping process before SARS high incidence comes. The superior relative humidity is propitious to SARS incidence. The abnormal change of climate is the inducement of SARS [13-17]. Throughout history, the occurrence of major plagues is related to climate anomalies. There were also obvious climatic anomalies before the occurrence of COVID-19. 
Joint report identified 174 SARS-CoV-2 infections throughout December in 2019, of which only some of the 74 clinically confirmed cases may be confirmed cases [1]. The details of these patients have not been released, and many cases are retrospectively investigated. In addition, patients with mild and asymptomatic infections are rarely recorded. Therefore, this article does not attempt to correlate climate with the date of onset of the case.

The temperature in winter 2019 is higher than in previous years. The cold wave caused by strong cold air will significantly increase the mortality and morbidity of cardiovascular, cerebrovascular, and respiratory diseases. Fig. 2 and Fig. 3 show the daily maximum temperature trends in November and December from 2011 to 2019, respectively. Between 11.23 and 11.25 in 2019, a large temperature drop occurred in Wuhan, and the temperature remained low for 7 days after the temperature drop (Fig. 2).

Table S1 gives an overview of the weather in Wuhan in 2017, 2018, and 2019 (clear, overcast, cloudy, rain, snow, fog, and wind). Fig. 4 and Fig. 5 show the average temperature and statistics of rainy days of Wuhan in November, December, and January from 2011 to 2020, respectively. The winter of 2019.11 to 2020.1 is very special, and the main feature is the existence of multiple mutations. Details as follows.

(1) The weather in November and December of 2019 has changed abruptly. $\otimes$ From Fig. 2, it can be seen that the temperature drop range from 11.24 to 11.25 in 2019 is as high as $15^{\circ} \mathrm{C}$, which is the largest temperature drop during the same period in history. The temperature of 11.25 is only $3{ }^{\circ} \mathrm{C}$, and the temperature for 7 consecutive days from 11.25 to 12.1 is less than $10^{\circ} \mathrm{C}$. The temperature on November 23,2016 was the lowest temperature in the history of the month, but after this day, the temperature was higher than the same period in 2019, and there was no continuous rain. From Table S1, there was only one light rain from 2016.11.24 to 2016.11.30, and the rest were cloudy or sunny. The weather for the six days from 2019.11 .18 to 11.23 was overcast, light rain, cloudy, overcast, sunny, cloudy, and first wind, light wind, light wind, light wind, light wind, light wind. The reason for the heavy cooling of 11.25 was the northeast wind 6 and light rain on 11.24, which was in sharp contrast to the 5 days of breeze and 1 day of level 1 wind in the previous 6 days. There was also a heavy temperature drop at 11.17 (Fig.2), and there was also a light rain that day. The reason for the heavy temperature drop was northwest wind level 6. Before 11.17, the number of sunny, cloudy, and overcast days from 11.1 to 11.16 was 6,6 , and 4 , respectively, which is rare in good weather compared to before 2019. From 2011-01-01 to 2020-03-01, there were no gales above 6 in Wuhan, and 6 gales occurred only in 3 days. Two of them occurred in 2019.11, all of which caused a large temperature drop. Among them, the great cooling of 11.25 is the largest cooling in November ever. In November and December of 2011-2019, Wuhan experienced only one heavy rain on December 18,2019 , and the rest was light or moderate rain. $\otimes$ From Table $S 1$, there was no rain between 12.1 and 12.16 in 2019, and there were 11 days of breeze. On December 17th and December 18th, two large temperature changes occurred, which were $8{ }^{\circ} \mathrm{C}$ and $13^{\circ} \mathrm{C}$, and the historical rankings are 4 and 1, respectively. The high temperature of 12.17 jumped from $11^{\circ} \mathrm{C}$ at 12.16 to $19^{\circ} \mathrm{C}$, and then quickly dropped to $6^{\circ} \mathrm{C}$ at 12.18 . The winds from 12.16 to 12.18 were level 2 . The reason for the heavy temperature drop at 12.18 was the only heavy rain in December in history, while the rest was light or moderate rain. 
The two heavy winds of November 6 and heavy rain in December 2019 is responsible for the pneumonia epidemic, especially the two strong winds of six. There was very little wind for 6 days before the strong wind and a big temperature drop of 11.24. If the wind in the environment is strong, the wind will dry the environment and blow away the accumulated virus, which will greatly reduce its toxicity. The seafood market has small outdoor wind and no wind indoor, which is conducive to virus reproduction. There are many virus clusters. When encountering heavy rain, it will flow to the nearby area with sewage overflowing. Strong winds, heavy rains, and severe drops in temperature make people less resistant to diseases and are susceptible to diseases.

(2) From Fig. 4, the historical rankings in the same period of the average daily low temperature, average daily high temperature, and average daily temperature in November 2019 were 3, 2, and 2, respectively. The historical rankings of these three parameters in December 2019 were 2, 1, and 1, respectively. The temperature in January 2020 showed no obvious pattern, but its rainy day was 13 days, the highest in the same period of history, and the second (2016.1) was only 8 days (Fig. 5). Bad weather has significantly increased the number of patients in Wuhan. From January 13th to 22nd, the major hospitals in Wuhan were already overcrowded, and it took ten hours to wait for a needle. The general trend of the climate change from November 2019 to January 2020 is from the warm winter of November and December to the cold winter of January (the temperature is not very low, but it is rainy).

Why did the COVID-19 occur in Wuhan? The origin is that the special circumstances of Wuhan's dense population, a large proportion of the floating population, and extremely developed transportation have encountered extreme climatic. According to the weather change, the development of the COVID-19 epidemic in Wuhan can be divided into three stages: (1) The strongest wind and light rain on November 17,2019 , and the strong cooling caused. The temperature began to drop sharply on November 24 and the rainy weather continued for 7 days. (2) Heavy rain and strong cooling on December 17 and 18, 2012. (3) Rain and rain in January 2020.

Based on the above analysis, Fig. 6 shows the historical evolution of the occurrence of new coronavirus pneumonia in Wuhan.

\section{Conclusions}

The seafood market was indeed the origin of the Wuhan epidemic. The probability of respiratory transmission is low in open space, while food transmission is possible.

Both the outbreak the SARS in Beijing in 2003 and the COVID-19 in Wuhan in 2019 were related to extreme weather. The general trend of the climate change from November 2019 to January 2020 is from the warm winter of November and December to the cold winter of January (the temperature is not very low, but it is rainy). The weather in November and December of 2019 has changed abruptly. From the end of 2019 to the beginning of 2020, there are a lot of extreme weather events in Wuhan from the end of 2019 to the beginning of 2020, including strong winds, heavy rains, large cooling after continuous high temperature, and continuous low temperature after large cooling It is rainy, the temperature suddenly rises 
and then drops rapidly, the wind continues to weaken for many days and then suddenly increases, and long rainy days, etc. The first COVID-19 case appeared in Wuhan in November, and the major outbreak began in late November. The origin of COVID-19 is mainly due to the drastic drop in temperature starting from November 24, 2019, and the rainy weather for 7 consecutive days. According to the weather change, the development of the COVID-19 epidemic in Wuhan can be divided into three stages: (1) The temperature began to drop sharply on November 24 and the rainy weather continued for 7 days. (2) Heavy rain and strong cooling on December 17 and 18, 2012. (3) Rain and rain in January 2020.

\section{Declarations}

Conflict of Interest: The authors declared no conflict of interest.

Funding Statement: This work was supported by the National Natural Science Foundation of China (51971204).

Author's Contribution: The first author led the drafting of this article, to which all authors contributed.

Availability of data and material $\triangle A / l$ data generated or analysed during this study are included in this published article and its supplementary information file.

Code availability: Not applicable.

Ethics approval: Not applicable.

Consent to participate: Not applicable.

Consent for publication: Not applicable.

All parts of this paper are related to the manuscript.

There are no articles for biological purposes.

\section{References}

1. Yang MH. WHO-China joint research report: summary report (in Chinese). https://www.jiemian.com/article/6209537.html.2021.6.9.

2. Deslandes A, Berti V, Tandjaoui-Lambotte $Y$, et al. SARS-CoV-2 was already spreading in France in late December 2019. Int J Antimicrob Agents, 2020, 55 (6): 106006. https://doi.org/10.1016/j.ijantimicag.2020.106006.

3. La Rosa G, Mancini P, Bonanno Ferraro G, et al. SARS-CoV-2 has been circulating in northern Italy since December 2019: Evidence from environmental monitoring. Sci Total Environ, 2021, 750:141711. https://doi.org/10.1016/j.scitotenv.2020.141711. 
4. Forster P, Forster L, Renfrew C, et al. Phylogenetic network analysis of SARS-CoV-2 genomes. Proc. Natl. Acad. Sci. USA, 2020, 117(17): 9241-9243. doi: 10.1073/pnas.2004999117.

5. Li PH, Li JH, Li LZ, et al. Genome evolution and intraspecific variation of SARS-CoV-2 (in Chinese). Mil Med Sci, 2020, 44(4): 241-245.

6. Ma Y, Zhao Y, Liu, J, et al. Effects of temperature variation and humidity on the death of COVID-19 in Wuhan, China. Sci Total Environ, 2020, 724: 138226. doi: 10.1016/j.scitotenv.2020.138226.

7. Iqbal N, Fareed Z, Shahzad F, et al. The nexus between COVID-19, temperature and exchange rate in Wuhan city: New findings from partial and multiple wavelet coherence. Sci Total Environ, 2020, 729: 138916. https://doi.org/10.1016/j.scitotenv.2020.138916.

8. Liu XD, Yun XL. Analysis of the correlation between the new coronavirus pneumonia (COVID-19) based on meteorological factors and the theory of luck (in Chinese). J Gulzhou Univ Tradit Chin Med, 2020, 42(2): 11-15.

9. Li XF, Du WX. Some thoughts on pneumonia caused by new coronavirus infection based on the theory of Five Yun and Six Qi (in Chinese). Chin Arch TCM, 2020, 38(3): 13-16.

10. Zhou MX. Identification and prevention of pneumonia caused by novel coronavirus pneumonia (in Chinese). Acta Chin Med, 2020, 35(2): 227-231.

11. Fan YP, Wang YP, Zhang HM, et al. Analysis of the treatment of new coronavirus pneumonia (COVID 19) from the cold epidemic treatment (in Chinese). J TCM, 2020, 61(5): 369-374.

12. Chen ZH, Yang HQ, Zhang HY, et al. Study on meteorological prediction of respiratory and cardiovascular diseases in Wuhan (in Chinese). J Hubei Coll TCM, 2001, 3(2): 15-17.

13. Zhang YL, Shou SW, Zhang P et al. Synoptic and climatic features during SARS spreading in China in 2003 (in Chinese). Meteorological, 2004, 30(2): 46-49.

14. Zhu FY, Sun YF, Song MJ, et al. The research of the relativity between the medical meteorology and SARS epidemic (in Chinese). Chin J Inf TCM, 2005, 12(3): 21-23.

15. Xie M, Liu T, Lu XA, et al. Correlation research between SARS ' propagation incidence and concentration of inhalable particulates in air in Guangzhou. J Saf Environ, 2004(3):73-76.

16. Sun WS, Wu XL, Qiao CL, et al. Retrospective analysis of the correlation between the epidemic law of SARS in China and the Five Movements and Six Circumstances (in Chinese). JETCM, 2004(11): 713$715+712$.

17. Gao SH, Wang CY, Zhang N, et al. Research on the correlation between SARS epidemic and natural climate change in Beijing area. Special academic exchange album on prevention and treatment of SARS with traditional Chinese medicine, 2003: 351-357.

18. Hu B S, Gong J H, Sun J, et al. Exploring the epidemic transmission network of SARS in-out flow in mainland China (in Chinese). Chin Sci Bull, 2013, 58(Z1):452-464. doi: 10.1007/s11434-012-5501-8

19. Huang C, Wang Y, Li X, et al. Clinical features of patients infected with 2019 novel coronavirus in Wuhan, China. Lancet, 2020, 395: 497-506. 
20. Ma J. Coronavirus: China's first confirmed COVID-19 case traced back to November 17. South China Morning Post, 13 March 2020; www.scmp.com/news/china/society/article/3074991/coronaviruschinas-first-confirmed-covid-19-case-traced-back.

21. Lin QS, Hu TJ, Zhou XH. Estimating the daily trend in the size of the COVID-19 infected population in Wuhan. Infect Dis Poverty, 2020, 9(1): 69.doi: 10.1186/s40249-020-00693-4.

22. Zhang $X$, Tan Y, Ling Y, et al. Viral and host factors related to the clinical outcome of COVID-19. Nature, 2020, 583: 437-440.

23. Andersen KG, Rambaut A, Lipkin WI, et al. The proximal origin of SARS-CoV-2. Nat Med, 2020, 26: 450-452.

24. Yu WB, Tang GD, Zhang $L$, et al. Decoding the evolution and transmissions of the novel pneumonia coronavirus (SARS-CoV-2 / HCoV-19) using whole genomic data. Zool Res, 2020, 41(3): 247-257. doi: 10.24272/j.issn.2095-8137.2020.022.

25. Benvenuto D, Giovanetti M, Salemi M, et al. The global spread of 2019 - nCoV: a molecular evolutionary analysis. Pathog Glob Health, 2020, 114(2): 64-67.

26. Li X, Zai J, Wang X, et al. Potential of large 'first generation' human-to-human transmission of 2019nCoV. J Med Virol, 2020, 92(4):448-454.doi: 10.1002/jmv.25693.

27. Pekar J, Worobey M, Moshiri N, et al. Timing the SARS-CoV-2 index case in Hubei province. Science, 2021, 372(6540): 412-417. doi: 10.1126/science.abf8003.

28. Editorial department. Novel Coronavirus Pneumonia: How can we respond scientifically to this battle without gunpowder (in Chinese). Technol Today, 2020(2): 52-54.

29. Wang D, Hu B, Hu C, et al. Clinical characteristics of 138 hospitalized patients with 2019 novel coronavirus-infected pneumonia in Wuhan, China. JAMA, 2020; 323(11): 1061-1069.

30. Lost opportunity, neglected small hospital cases in the early stage of the new crown epidemic (in Chinese). https://xueqiu.com/1553077980/140930217. 2020.2.11.

31. Life and death related to Jinyintan (in Chinese).

http://www.nhc.gov.cn/xcs/fkdt/202003/9502b2d78ea94ea9a43e855ca9e0a5e2.shtml. 2020.3.9.

32. Liu RZ. Listening to the thunder in the silent place: Observation and thinking of a scientific and technological worker after the city was closed in Wuhan (in Chinese). Surf Eng Remanuf, 2020, 20(Z1): 10-18.

33. Li X, Zhou L, Jia T, et al. The impact of urban factors on the COVID-19 epidemic--taking Wuhan City as an example (in Chinese). Geomatics Inf Sci Wuhan Univ, 2020, 45(6): 826-835.

34. The East Lake Lantern Festival was on CCTV and received more than 20,000 tourists on the two days of its opening (in Chinese). http://www.whtv.com.cn/p/18175.html. 2020.1.1.

35. What are the activities of Wuhan East Lake Lantern Festival on New Year's Eve 2020? (in Chinese). http://www.wuhan.com/travel/37486.html. 2020.1.17.

36. The theatrical performance of the Hubei Spring Festival group visit was held in Wuhan and ended successfully! (in Chinese). https://baijiahao.baidu.com/s? 
id $=1656625173766447067 \&$ wfr $=$ spider\&for=pc. 2020.1 .24 .

37. Baidu Encyclopedia: 2019 Wuhan Military Games (in Chinese).

38. Mu SX. Why does the SARS virus prefer Beijing? (in Chinese). http://blog.sina.com.cn/s/blog_544838700100i5q2.html. 2010.4.7.

39. Ding DP. The characteristics of sand and dust weather and circulation in the spring of 2003 in Beijing (in Chinese). Proceedings of the "Urban Meteorology and High-tech Olympics" Branch of the 2003 Annual Meeting of the Chinese Meteorological Society. 2003:53-57.

40. The weather in Beijing last year set a number of records in a century (in Chinese). http://news.hebei.com.cn/system/2003/01/03/005888551.shtml. 2003.1.3.

41. Huang $Y$, Wang $L$, Cao $M$, et al. A review on the environmental transmission of novel coronavirus (SARS-CoV-2) (in Chinese). Environ Chem, 2021, 40 (7): 1945-1957.

42. Ren Me, Chen J, Jiang T, et al. Status and perspectives on the study about the associations of environmental temperature and humidity with COVID-19 transmission. Environ Chem, 2020, 39(6) : 1473-1478.

43. Tang $\mathrm{J} W$. The effect of environmental parameters on the survival of airborne infectious agents. $J R$ Soc, Interface, 2009, 6(Suppl 6): S737-S746.

44. Riddell S, Goldie S, Hill A, et al. The effect of temperature on persistence of SARS-CoV-2 on common surfaces. Virol J, 2020, 17(1): 145.

45. Adelodun B, Ajibade F O, Tiamiyu A O, et al. Monitoring the presence and persistence of SARS-CoV-2 in water-food-environmental compartments: State of the knowledge and research needs. Environ Res, 2021; 200: 111373. doi: 10.1016/j.envres.2021.111373

\section{Figures}




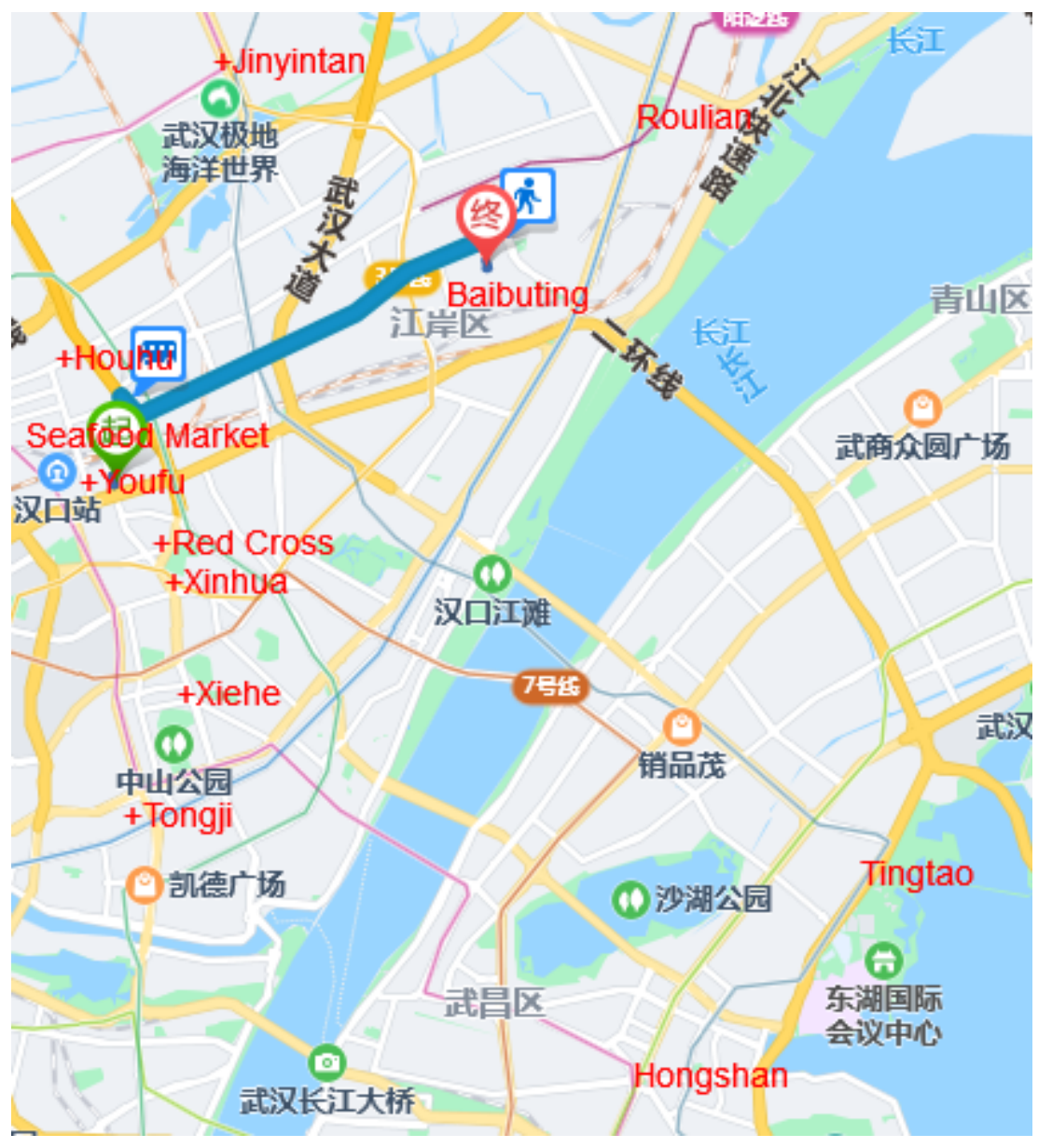

Figure 1

Geographical information of the South China Seafood Market, hospital, Baibuting, etc. related to the outbreak of the Wuhan epidemic. Note: Red cross - Hospital, Roulian - Wuhan Roulian Food Co., Ltd., Hongshan - Hongshan Auditorium. Event: 2019.12.31-1.21, East Lake Lantern Festival; 2020.1.18, Banquet for ten thousand families; 2020.1.21, Literary performance. 


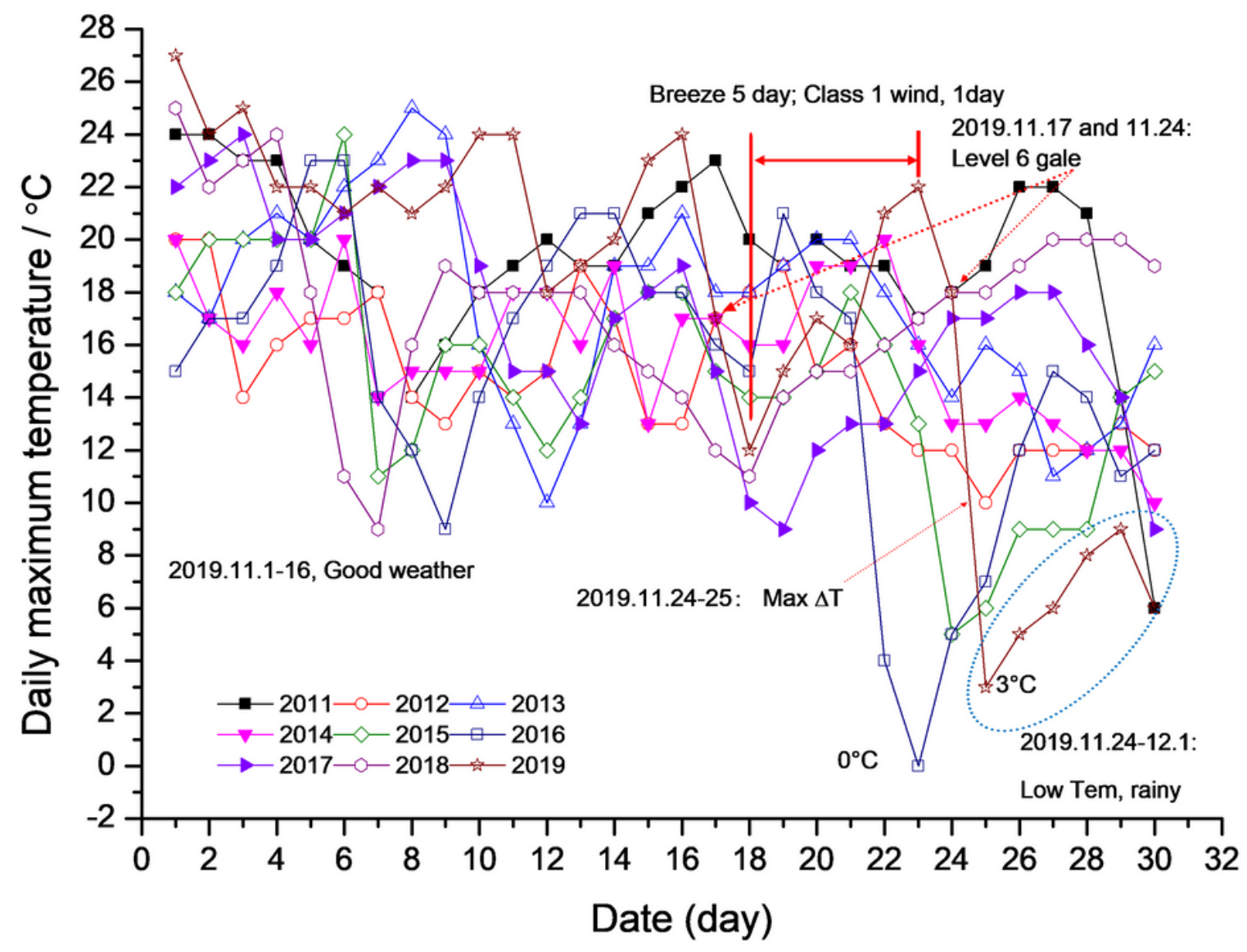

Figure 2

Chart of daily maximum temperature in November (2011 - 2019). 


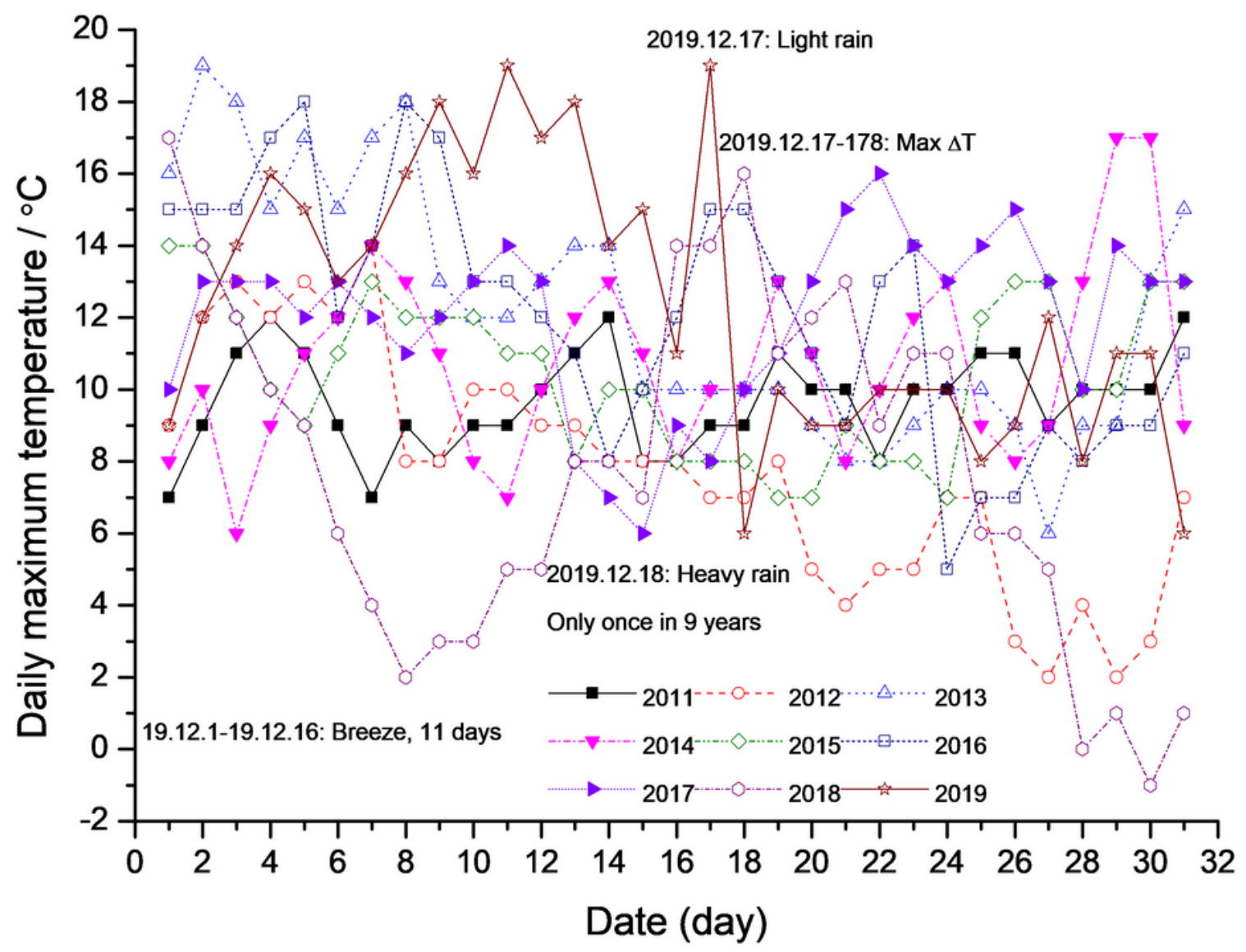

Figure 3

Chart of daily maximum temperature in December (2011 - 2019). 


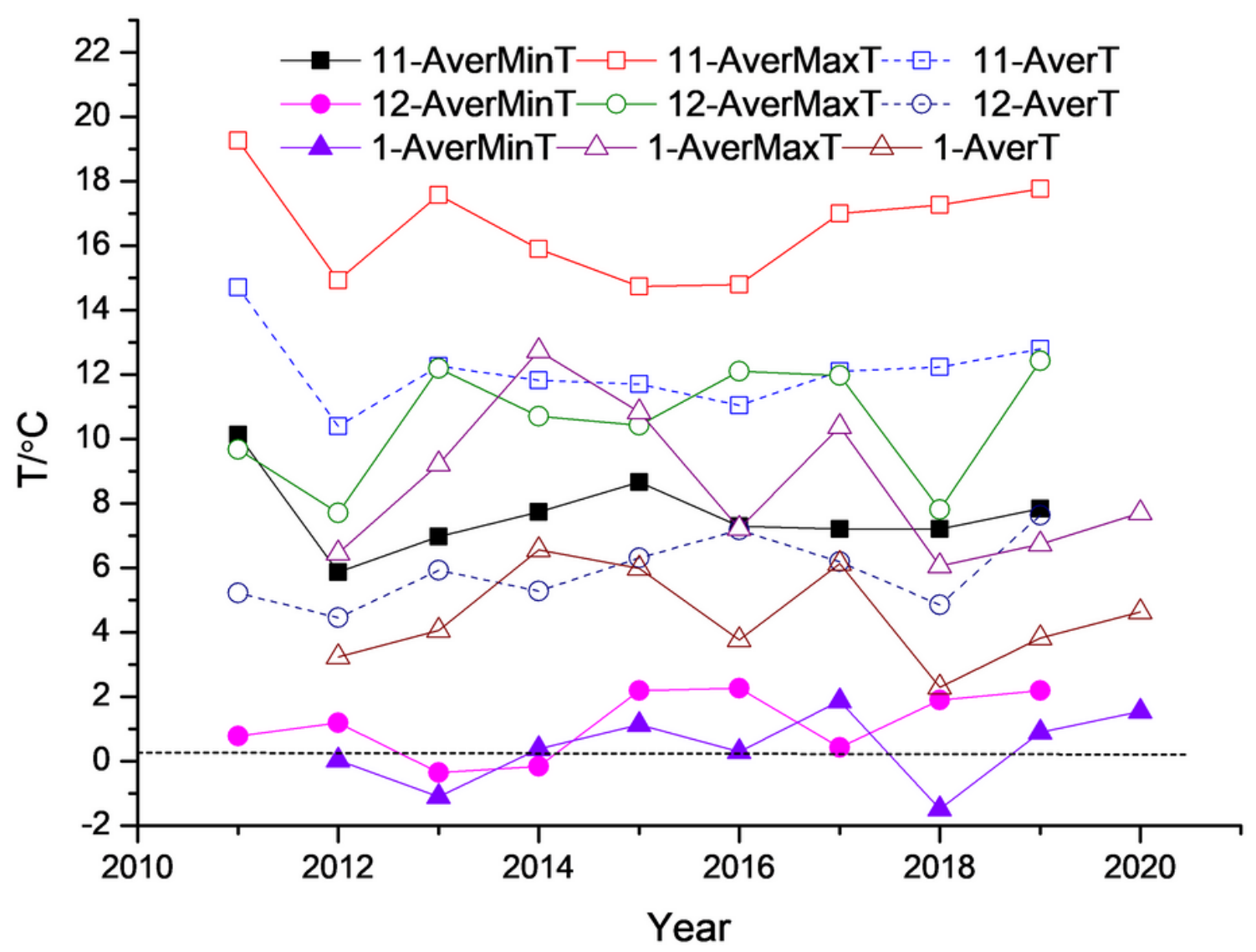

Figure 4

The average temperature of Wuhan city in November, December, and January (2011 - 2020). Average daily maximum temperature (AverMaxT) $=\Sigma$ daily maximum temperature/days; Average daily minimum temperature $($ AverMinT $)=\Sigma$ daily minimum temperature/days; Average daily temperature $($ AverT $)=$ (average daily maximum temperature + average daily minimum temperature) / 2 . 


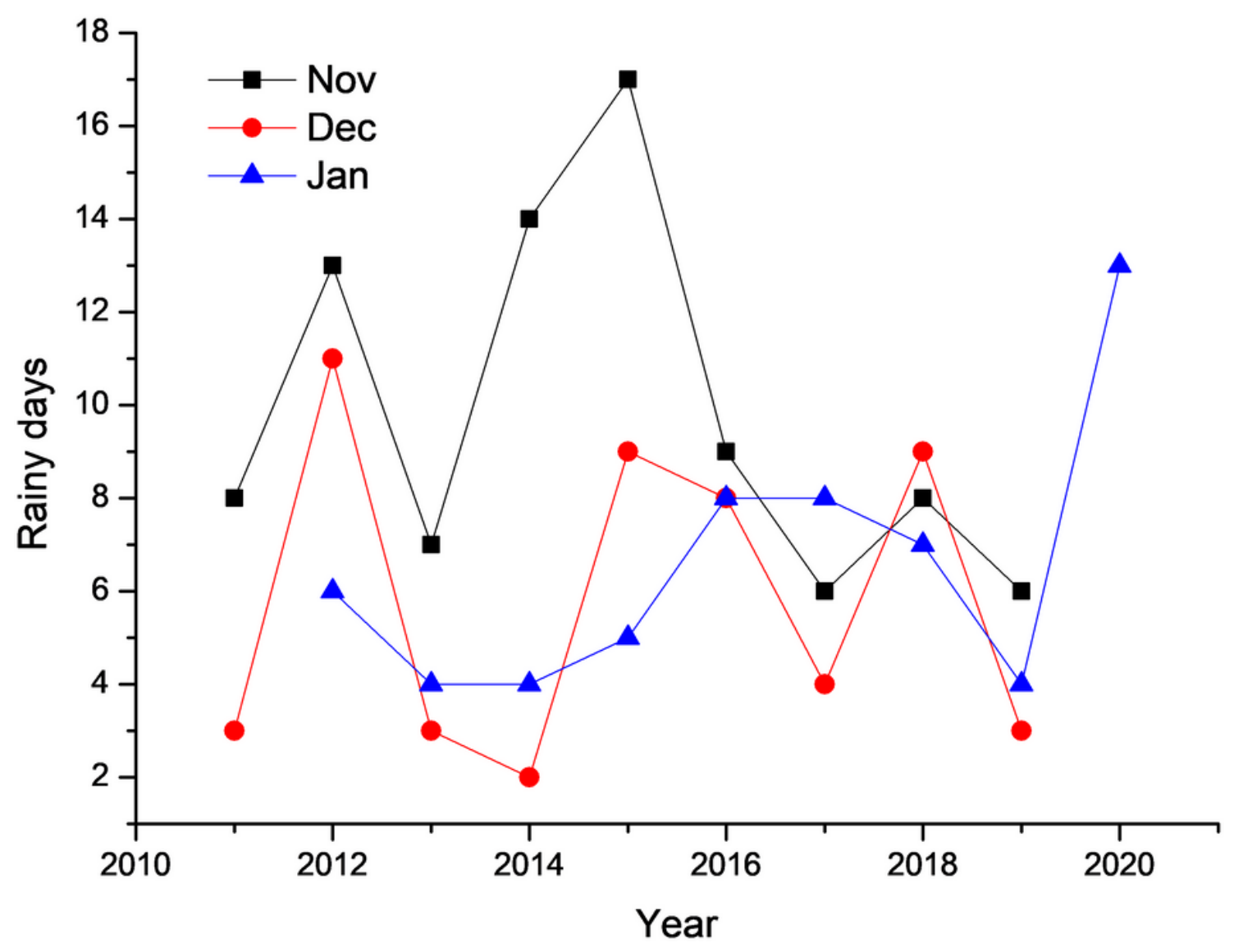

Figure 5

Statistics of rainy days in November, December, and January (2011 - 2020). 


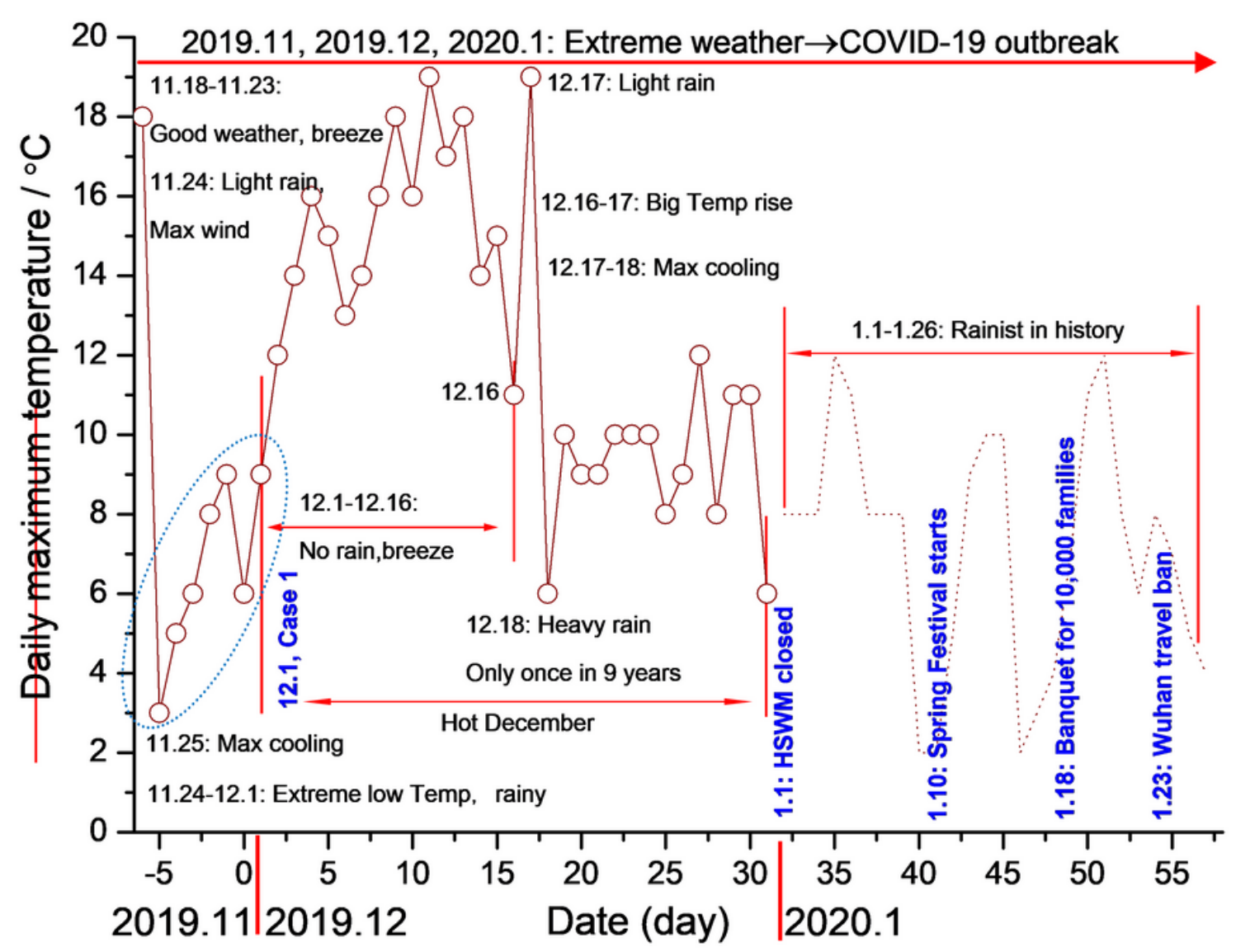

Figure 6

Historical evolution of COVID-19 pneumonia in Wuhan city.

\section{Supplementary Files}

This is a list of supplementary files associated with this preprint. Click to download.

- renamedcd2a1.docx 